\title{
Nutritional Status and the Associated Factors in Under Five Years Children of Lamjung, Gorkha and Tanahun Districts of Nepal
}

\author{
Govinda Prasad Dhungana
}

Submitted: 28 May 2017; Accepted: 20 July 2017

\begin{abstract}
Background: The nutritional status of children is important as it determines their health, physical growth as well as development, productive life and academic performance. The national figures for stunting, underweight and wasting in under five years children in Nepal stands at $41 \%, 29 \%$ and $11 \%$, respectively according to NDHS 2011 . However, the magnitude of this problem in hilly areas of Nepal is not well understood.

Objectives: The objective of this study was to find the nutritional status of 6 to 59 months of children and its associated factors.

Materials and Methods: A cross-sectional, population-based study design has been used for this study. The study population was 6 to 59 months children who were permanent or temporary residents of the study area. The respondent was the mother of the under 5 year child. A total $10 \%(n=1353)$ study participants were selected from each of the 4 VDCs of Lamjung and Gorkha, and each of the 5 VDCs of Tanahun during April-May, 2014 by applying systematic random sampling. A semistructured questionnaire was administered to mothers by face to face interview method. The anthropometric measurements (weight and height) were also recorded. Binary logistic regression was applied to identify the factors associated to the nutritional status.

Results: In the study, $56.3 \%$ were boys and $43.7 \%$ were girls. The prevalence of wasting, stunting and underweight was $10.6 \%$ (95\% C.I: $9.0-12.2$ ), $53.9 \%$ (95\% C.I: $51.2-56.6)$ and $20.8 \%$ (95\% C.I: 18.6-23.0), respectively. The wasting, stunting and underweight were higher in boys than in girls. The factors were duration of breast feeding, occupation of mothers, family size, site of delivery, height of mothers and age of mother during the delivery.

Conclusion: Stunting was more prevalent than wasting in the study districts and implies that there is a problem of chronic malnutrition. The factors highlighted in this study should be adequately addressed by concerned authorities to address malnutrition in these hilly districts of Nepal.
\end{abstract}

Keywords: Children, district, Nepal, stunting, underweight, wasting.

Address correspondence to the author: Birendra Multiple Campus, Chitwan

Email: dhunganagovindana2012@gmail.com 


\section{INTRODUCTION}

The nutritional status of infant and under five years children is an important factor as it determines their health, physical growth as well as development, productive life and academic performance (Ronsmans, Collin, \& Filippi, 2008). Nutritional well-being of the population is crucial for accelerated attainment of many of the Sustainable Development Goals (National Planning Commission [NPC], 2015). Malnutrition is a major public health problem in most of the developing countries and is more common among under-five years children (Bhandari and Chhetri, 2013; Masood-us-Syed, Saleh and Butt, 2011; Chatuat and Khanal, 2016). It can be a major deterrent to achieving national, economic and social goals and targets as it reduces child survival and can adversely affect physical development and cognitive function of a child. Malnutrition also perpetuates the malnutrition-infection cycle, leading to considerable morbidity and mortality in children under five years of age. Globally, the prevalence of wasting, stunting and underweight is $8 \%$, $37.4 \%$ and $15.7 \%$ respectively. South Asia has the highest prevalence of malnutrition as compared to other regions and the prevalence of wasting, stunting and underweight is $10 \%, 39 \%$ and $19.3 \%$ respectively (WHO, 2016).

In Nepal, the prevailing high rate of child under nutrition is one of the major nutritional problems despite a steady decline in past several years. The prevalence of wasting, stunting and underweight in Nepal is $11.3 \%, 41 \%$ and 29\% (Nepal Ministry of Health and Population, New ERA and ICF International, 2012; UNICEF, WHO, \& World Bank, 2016). The children in the rural areas of Nepal are more prone to malnutrition (wasting, stunting and underweight) than the children in the urban areas (WHO, 2016). Among the under five years children, in a span of 10 years (from 2001 to 2011), the percentage of stunting came down from $57 \%$ to $41 \%$; the percentage of wasting was at $11 \%$ and the percentage of underweight came down from $43 \%$ to $29 \%$ (Department of Health Services [DoHS], 2016). However, in spite of vigorous efforts and community based nutritional interventions carried out by the Government, we were unable to meet the Millennium Development Goal (MDG) targets for nutrition (DoHS, 2016). The Global Nutrition target aims to reduce the global number of children under five who are stunted by 40 percent and aims to reduce and maintain childhood wasting to less than 5 percent (DoHS, 2016). In order to meet these targets, Nepal needs to address various factors that are associated with under nutrition.

Several factors have been found to be associated with malnutrition in Nepal. Malnutrition is affected by individual variations, household variations, variations in community, lack of knowledge related to health and nutrition, economic constraints, malpractices, social and cultural factors (Haileslassie, Mulugeta and Girma, 2013; Pandey et al., 2013) household food insecurity, frequent 
illness and infections, poor environmental practices, inadequate dietary intake, poor hygiene, eating of fast foods, vaccination status of child, breast feeding as well as maternal factors (DoHS, 2016). When combined with these factors, the cycle of intergenerational malnutrition comes into existence and continues. The nutritional status and its associated factors haven't been explored adequately in Lamjung, Gorkha and Tanahun, Hence the present study was carry out to explore the nutritional status and its associated factors in these hilly districts of Nepal.

\section{MATERIALS AND METHODS}

A cross- sectional, analytical, population - based study design has been used for this study. The study population was under five years (6 to 59 months) children who were permanent or temporary residents of the study area. The study areas were three hilly districts of Nepal (Lamjung, Gorkha and Tanahun). The sampling was done in two stages. In the first stage, the Village Development Committees (VDC) was selected and in the second stage, selection of under 5 years children was done. A random sampling technique was used to select the VDCs and study subjects were selected from each of the 4 VDCs of Lamjung (Duradada, Chandreswor, Jita and Chakratirtha), each of the 4 VDCs of Gorkha (Finam, Bungkot, Namjung and Taple), and each of the 5 VDCs of Tanhun (Risti, Kyamin, Symgha, Ghansikuwa and Jamune Bhanjyng) for indistinguishable number of study subject. In the second stage, a sampling frame was created using the list of under 5 year children in each selected VDCs separately called second stage units (SSU).Total under 5 years children in 13 SSU were 14060 available during the data collection period. The sampling unit was under 5 years children .The sampling unit was selected by using systematic random sampling. One under 5 years child was selected at random from each SSU and then every $10^{\text {th }}$ under 5 year child was selected in each SSU. A total of $1405(\approx 10 \% 14060)$ of under 5 year children were selected, out of these 1405 children, only those with complete information i.e. 1353 (96.3\%) were included in the final data analysis. The respondent was the mother of the under 5 year child.

The height/length and weight were measured for all children. The height of child $\geq 24$ months was measured by making the child stand bare feet on a flat and even floor against a wall and with feet parallel and joined together and with heels and buttock touching on the wall. It was made sure that head was held erect and hands were hanging closely at the sides. The height was marked on the wall with the help of a ruler and measured with a tape. The recumbent length of the child $<24$ months was taken by keeping the foot plantar flexed, the knee extended and the forehead touching the wall and this was done with the help of an assistant. The weight of the child more than one year was taken using a bathroom scale, which was calibrated every single time the weight was taken. The weight of the child less than one year was measured as follows - Initially, the weight was taken for the child 
along with the mother while the mother held the child. After that, only the mother's weight was taken and this weight was then subtracted from the previous weight to get the actual weight of the child. The nutritional status in this study is classified according to the criteria given in World Health Organization (WHO) Growth Standard 2006 (WHO, 2006). A height for age below minus two Standard Deviation (SD) to minus three SD is considered as Moderate Stunting; a height for age which is minus three SD is considered as Severe Stunting ; a weight for height which is below minus two SD to minus three SD is considered as Moderate Wasting; a weight for height which is minus three SD is considered as Severe Wasting; a weight for age which is below minus two SD to minus 3SD is considered as Moderately Underweight and a weight for age which is minus three SD is considered as Severely Underweight.

The data collection was carried out from 22 April to 10 May, 2014. The data collection tool was a semi-structured interview schedule and the data collection method was face-to-face interview. The data was collected by medical students after orientation and training for 7 days. The data was checked for completeness and accuracy and there after entered in Epi Data 3.1. This data was exported into IBM SPSS 20 version and WHO Anthro for further analysis. The Z score was calculated by using the WHO Anthro software. The data was analyzed by using descriptive and inferential statistics. The frequency, mean and SD were calculated in univariate analysis. For bivarate analysis, the chi square test was applied to test the association between the three types of malnutrition and the predictor variables. The $5 \%$ level of significance $(\mathrm{p}<0.05)$ was taken to be statistically significant. Odds ratio was calculated only for significant variables. Variables which were significant in bi-variate analysis were modeled into multivariate analysis by using logistic regression. The logistic regression was validated using Hosmer and Lemeshow chi square test for goodness of fit, Pseudo $\mathrm{R}^{2}$ (Cox \& Snell R Square) and Nagelkerke R Square. In multivariate analysis, only few variables were significant that might be Pseudo $\mathrm{R}^{2}$ was low in fitted model. Also, Variance Inflation Factors (VIF) test was applied for diagnosis of multicoliniriaty.

\section{RESULTS}

\section{Characteristics of study subjects}

A total of 1,353 children were enrolled in the study (36.8\% children from Lamjung, $31.9 \%$ children from Tanahun and $31.3 \%$ children from Gorkha). A total of $60.2 \%$ children were living in joint family and $39.8 \%$ children were living in nuclear family. As regards family size, $27.1 \%$ children had $\leq 4$ family members, $46.3 \%$ had $5-6$ family members and $26.5 \%$ had $\geq 7$ family members. The Mean \pm SD of family size was $6 \pm 2$. More than half $(57.4 \%)$ of the mothers were engaged in Agriculture. Most of the mothers (82\%) had attended school. Less than half $(43.1 \%)$ of the mothers 
consumed more food than usual, during pregnancy. Most of the mothers $(89.4 \%)$ followed no restriction on any types of food while $10.6 \%$ mothers followed restriction of food. Out of the total respondents, $72.8 \%$ respondents delivered at government hospitals (Table 1).

Table 1. Characteristics of mothers of under five year children $(n=1353)$.

\begin{tabular}{lcr}
\hline Characteristics & Number & Percentage \\
\hline Occupation of mothers & 776 & 57.4 \\
Agriculture & 103 & 7.6 \\
Business & 474 & 35.0 \\
Service & & \\
Educational status of mothers & 114 & 8.4 \\
Illiterate & 114 & 3.4 \\
Can read and write & 490 & 22.9 \\
Basic education & 310 & 24.0 \\
Secondary & 325 & \\
Higher Secondary and above & & 43.1 \\
Food intake during pregnancy & 584 & 35.2 \\
More than as usual & 476 & 21.7 \\
As usual & 293 & \\
Less than as usual & & 10.6 \\
Food taboos during pregnancy & 143 & 89.4 \\
Yes & 1210 & 39.5 \\
No & & \\
Work load during pregnancy & 534 & \\
As usual & & \\
Delivery site & 368 & \\
Hospital & & \\
Home and on the way of hospital & & \\
\hline & & \\
& &
\end{tabular}

A total of (59.3\%) mothers exclusively breastfed their children for 6 months. Only $2.8 \%$ mothers breastfed their children for more than 2 years. Almost (90.4\%) mothers had fed colostrums to their children (Table 2). 


\section{Prevalence of malnutrition}

The prevalence of wasting was $10.6 \%$ (95\% C.I: 9.0-12.2), prevalence of stunting was $53.9 \%$ (95\% C.I: $51.2-56.6)$ and prevalence of underweight was $20.8 \%$ (95\% C.I: $18.6-23.0)$ among under 5 years children. The prevalence of wasting, stunting and underweight was higher in boys than in girls. A total of $4.43 \%(n=60)$ were severely wasted, out of which, $2.58 \%$ boys were severely wasted as compared to $1.85 \%$ girls. A total of $6.2 \%(n=84)$ children were moderately wasted, out of which, $3.39 \%$ boys were moderately wasted as compared to $2.81 \%$ girls.

Table 2. Breastfeeding practice among mothers of under five year children $(n=1353)$.

\begin{tabular}{lrr}
\hline Feeding practices & Number & Percentage \\
\hline Breastfeeding practice (in months) & 163 & 12.0 \\
< 6 months & 1079 & 79.7 \\
Up to 11 months & 47 & 3.5 \\
Up to 17 months & 26 & 2.0 \\
Up to 23 months & 38 & 2.8 \\
$\geq 24$ months & & \\
Colostrum feeding & 1223 & 90.4 \\
Yes & 122 & 9.0 \\
No & 8 & 0.6 \\
Don't know & & 59.3 \\
Exclusive breastfeeding & 802 & \\
6 months & & \\
\hline
\end{tabular}

A total of $39.32 \%(n=532)$ children were severely stunted, out of which, $22.69 \%$ were boys and $16.63 \%$ were girls. A total of $14.63 \%(n=198)$ children were moderately stunted, out of which, $8.57 \%$ were boys and $6.06 \%$ were girls. A total of $8.28 \%(n=112)$ children were severely underweight, out of which, $5.39 \%$ were boys and $2.87 \%$ were girls. A total of $12.5 \%(n=169)$ children were moderately underweight, out of which, $6.3 \%$ were boys and $6.2 \%$ were girls. There is a downward shift of curves throughout the under-five age while plotting age against mean z-score for height for age and for weight for age. Height for age stabilized around -1SD z-score till the age of 23 months. After 23 months, there is a sharp decrease in z- score as the age increased. Similarly, for weight for age, there is a continuous decrease in mean z-score from 23 months onwards. These findings reveal that the prevalence of stunting and underweight gradually increased after 23 months of age. The weight for height curve showed mean z-score to be positive in all age groups. The prevalence of wasting started decreasing from 35 months onwards (Figure: 1). 


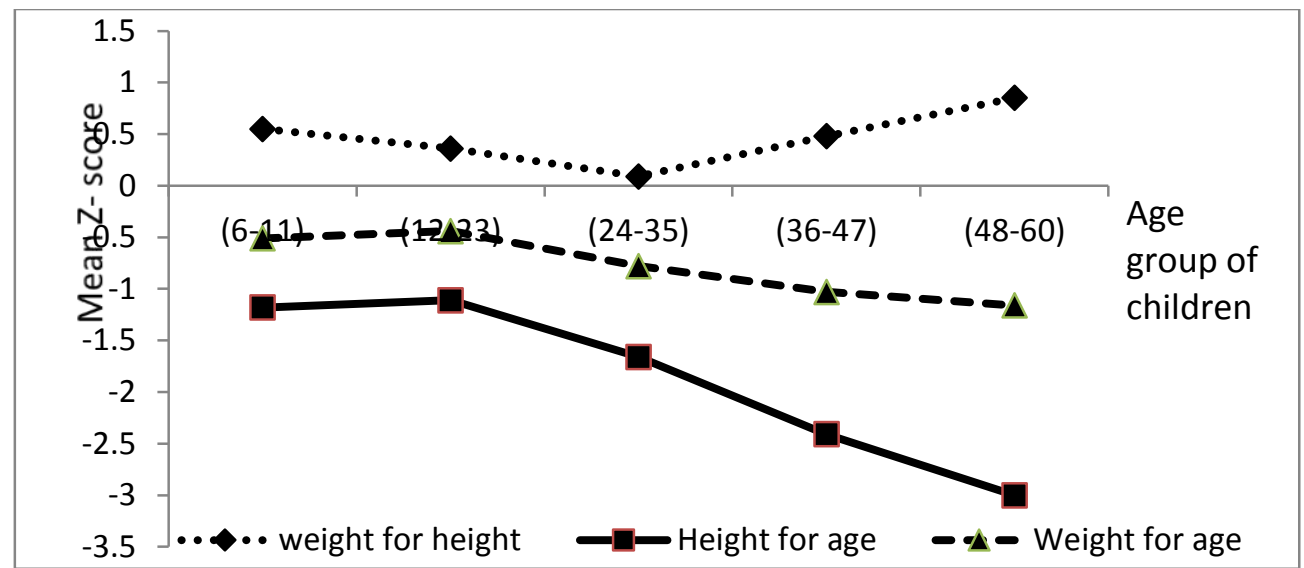

Fig. 1. Age wise distribution of mean z-score for weight for height, height for age, weight for age.

\section{Factor affecting weight-for-height, height -for-age and weight-for-age}

Those mothers who breastfed their children for $<6$ months, were 1.61 (95\% CI: 1.010-2.567) times more likely to have malnourished children than mothers who breastfed their children for $\geq 6$ months (Table No.3). Children of those mothers whose main occupation was service were 1.375 (95\% CI: 1.088-1.735) times more likely to be stunted as compared to children of mothers whose main occupation was agriculture. Children of those household whose family size was $\leq 4$ were 1.447 (95\% CI: 1.072-1.954) times more likely to be stunted as compared to children of household whose family size was $\geq 7$ (Table 3). Children of respondents who delivered at home or on the way to hospital were $1.603(\mathrm{AOR}=1.705,95 \% \mathrm{CI}$ : 1.236-2.350) times more likely to be underweight as compared to children of respondents who delivered at health institutions. Children of those mothers whose height was $\leq 145 \mathrm{~cm}$ were $2.125(\mathrm{AOR}=2.225,95 \% \mathrm{CI}: 1.288-3.841)$ times more likely to be underweight as compared to children of mothers who were $>145 \mathrm{~cm}$ in height. Children born to mothers who were $>35$ years of age, were 2.218 (95\% C.I: 1.217-4.043) times more likely to be underweight as compared to children born to mothers aged 20-35 years. Regarding the ethnicity, Dalit children were 1.590 (95\% CI: 1.106-2.287) times more likely to be underweight as compared to Brahmin children but in multivariate analysis there was no statistically significant association between ethnicity and age of mother during delivery with underweight (Table: 3 ). 
Table 3: Predictor (s) of wasting, stunting and underweight.

\begin{tabular}{|c|c|c|c|c|c|c|}
\hline \multirow[b]{2}{*}{ Breastfeeding } & \multicolumn{2}{|c|}{ Wasting } & \multirow[b]{2}{*}{ UOR } & \multirow[b]{2}{*}{ AOR } & \multirow[b]{2}{*}{$P$ value } & \multirow[b]{2}{*}{$95 \% \mathrm{CI}$} \\
\hline & $\begin{array}{c}\mathrm{NO} \\
n(\%)\end{array}$ & $\begin{array}{c}\text { Yes } \\
n(\%)\end{array}$ & & & & \\
\hline$\geq 6$ months & $1058(89.9)$ & $119(10.1)$ & 1 & & & \\
\hline$<6$ months & $138(84.7)$ & $25(15.3)$ & 1.611 & NA & 0.045 & $1.010-2.567$ \\
\hline \multicolumn{7}{|c|}{ Stunting $\dagger$} \\
\hline \multicolumn{7}{|l|}{ Occupation of mothers* } \\
\hline Agriculture & $386(49.7)$ & $390(50.3)$ & 1 & & & \\
\hline Business & $44(42.7)$ & $59(57.3)$ & 1.327 & 1.222 & 0.350 & $0.802-1.861$ \\
\hline Service & 193(40.7) & $281(59.3)$ & 1.441 & 1.375 & 0.008 & $1.088-1.735$ \\
\hline \multicolumn{7}{|l|}{ Family size* } \\
\hline$\geq 7$ member & $177(49.3)$ & $182(50.7)$ & 1 & & & \\
\hline 5-6 member & $304(48.5)$ & $323(51.5)$ & 1.033 & 1.013 & 0.921 & $0.781-1.315$ \\
\hline$\leq 4$ member & $142(38.7)$ & $225(61.30$ & 1.541 & 1.447 & 0.004 & $1.072-1.954$ \\
\hline \multicolumn{7}{|c|}{ Underweight } \\
\hline \multicolumn{7}{|l|}{ Delivery site* } \\
\hline Hospital & 802(81.4) & $183(18.6)$ & 1 & & & \\
\hline $\begin{array}{l}\text { Home and on the way } \\
\text { to hospital }\end{array}$ & $268(73.2)$ & $98(26.8)$ & 1.603 & 1.705 & 0.001 & $1.236-2.350$ \\
\hline \multicolumn{7}{|l|}{ Height of mothers* } \\
\hline$\geq 145 \mathrm{~cm}$ & $63(65.6)$ & $33(34.4)$ & 1 & & & \\
\hline$<145 \mathrm{~cm}$ & $1006(80.2)$ & $248(19.8)$ & 2.125 & 2.225 & 0.004 & $1.288-3.841$ \\
\hline \multicolumn{7}{|c|}{ Age of mother during delivery } \\
\hline 20-35 years & 806(79.3) & $211(20.7)$ & 1 & & & \\
\hline$>35$ years & $31(63.3)$ & $18(36.7)$ & 2.218 & 1.769 & 0.079 & $0.936-3.345$ \\
\hline \multicolumn{7}{|l|}{ Ethnicity } \\
\hline Brahmin & $290(80.8)$ & 69(19.2) & 1 & & & \\
\hline Chhetri & $194(80.8)$ & $46(12.9)$ & 0.997 & 0.945 & 0.804 & $0.593-1.499$ \\
\hline Janajati & $325(80.8)$ & $77(19.2)$ & 0.996 & 0.951 & 0.806 & $0.636-1.422$ \\
\hline Dalit & $222(72.5)$ & $84(27.5)$ & 1.590 & 1.442 & 0.082 & $0.954-2.178$ \\
\hline
\end{tabular}

1-Reference category, AOR- Adjusted odds ratio, CI-Confidence interval, UOR-Unadjusted odd ratio, NA-Not Applicable,* significant only in multivariate; $\uparrow$ Nagelkerke $R$ Square-0.018, Hosmer and Lemeshow test $\mathrm{p}$ value $=0.993,-2 \log$ likelihood $=1848.813$, VIF value $=1.004$, for stunting adjusted with occupation of mother and family size; $\$$ Nagelkerke R Square-0.043, Hosmer and Lemeshow test $P$ value $=0.756,-2 \log$ likelihood $=1048.036$, VIF value $=1.475$, for underweight adjusted with delivery site, height of mother, age of mother during delivery and ethnicity. 


\section{DISCUSSION}

In developing countries, malnutrition in children is a public health concern. Nepal is a developing country, where a huge number of people live below the poverty line and Nepal has got a high proportion of malnourished children of under-five years of age. This study showed that $53.9 \%$ were stunted, $10.6 \%$ were wasted and $20.8 \%$ were underweight in Lamjung, Gorkha and Tanahun Districts of Nepal. In NDHS 2011 (Nepal Ministry of Health and Population, New ERA and ICF International, 2012), stunted children were in lesser proportion (41\%), wasted children were almost in similar proportion (11\%) and underweight children were slightly higher in proportion (29\%). The findings of this study were different from findings of NDHS 2011. NDHS 2011 represented the Mountain, Hill and Tarai in all ecological regions but this study was concerned with only three hilly districts. This fact the finding was differing with NDHS 2011. The finding of Nepal Multiple Indicator Cluster Survey (NMICS) in 2014 (DoHS, 2016) shows that the prevalence of stunting is $37 \%$ which is lower as compared to this study, wasting is $11 \%$ which is similar to this study and underweight is $30 \%$ which is higher than in this study. The higher percentage of stunting in this study could be because of the fact that this study was conducted within the hilly region. Similar findings have been reported in various studies (Nepal Ministry of Health and Population, New ERA and ICF International, 2012; DoHS, 2016; Pradhan, 2010).

The prevalence of stunting in this study was observed to be higher as compared to wasting and underweight The studies conducted in sub-Saharan Africa, South Asia, Nairobi Kenya and Ethiopi showed similar results (UNICEF, 2013; Nungo, Okoth and and Mbugua 2012; Mengistu, Alemu and Destaw 2013). However, in contrast to this study, a study conducted in Western Kenya (Nungo et.al., 2012) revealed that $26.6 \%$ were stunted, $10.1 \%$ were wasted and $13.9 \%$ were underweight. Likewise in the study conducted in Sri Lanka (Peiris and Wijesinghe, 2010), 11.8\% were stunted, $42.7 \%$ were wasted and $41.2 \%$ were underweight. A study conducted in Pakistan (Lodhi, Lodhi Wazir, Taimoor and Jadoon, 2009) revealed that 20\% were stunted, $21 \%$ were wasted and $41.2 \%$ were underweight.

The above scenario shows that there is wide variation in malnutrition within and between the countries. This may be due to the fact that malnutrition is widely affected by socio-economic condition, socio-cultural practices, dietary habit, poverty, etc. and these factors are different by geographic locations. Regarding the malnutrition, boys were more wasted, stunted and underweight in comparisons to girls in this study. This finding was similar to findings from NDHS 2011. These findings were also similar to the findings of Kumar, Goel, Mittal and Misra (2006) probably because 
socio-cultural factors, economic factors and consumption of food pattern of Nepal and India bear a striking resemblance.

The Mean Z- score of height for age and weight for age was decreasing in trend after 23 months of birth. This finding was similar with the study of NDHS 2011 and Sapkota and Gurung (2009). This might be due to the fact that Nepal government is giving prime importance to infant and young child feeding (IYCF), which focuses on children less than 24 months. This finding could also be because of the fact that there is a growing physical demand for good nutrition beyond 23 months which is difficult to meet in poor households.

This study showed that more than half of the mothers (59\%) followed exclusive breastfeeding practice and this finding is slightly higher than the finding in MICS 2014 which states that exclusive breastfeeding is $56.9 \%$ nationally (UNICEF, 2016). However; this finding is lower than the finding in NDHS 2011 (70\%). This study showed that only $2 \%$ children were breastfed up to two years, indicating that optimal breastfeeding practices were not followed by the mother. This observation could be due to the fact that the mothers and family member were not much aware about the importance and need of breastfeeding for under 2 years children or they were not able to provide sufficient time to breastfeed due to daily workload/task. Inappropriate and inadequate breast feeding practices, can lead to stunting, wasting and underweight as well as reduce the learning ability, reduce resistance and immunity against infection and reduce the overall productivity in the future. It is therefore necessary to educate, counsel and motivate mothers for strict adherence to recommended breastfeeding practices so as to enhance the nutritional status of children. In this study, those mothers who breastfed their children for $<6$ months, were more likely to have malnourished children. This finding was supported by different studies as NDHS 2011, UNICEF (2016), DoHS (2016), Pandey et al. (2013), Sapkota et. al., (2009) and Dhungana (2014). Babies who are not exclusively breastfeed are more likely to have lower immunity which makes them susceptible to infection and this in turn perpetuates malnutrition.

Around 57\% of mothers did not take sufficient food during the pregnancy period. Nearly $10 \%$ of mothers had food taboos during the pregnancy period. Around $40 \%$ of mothers continue with their usual physical work during pregnancy period. All these factors could have led to a high prevalence of stunting in this study. In this study, those children whose mothers engaged in service or business work were more likely to be malnourished. Similar findings were found in a study conducted by Ruwali D., in Padampur VDC of Chitwan, Nepal (Ruwali, 2014). This observation could be because of the facts that mothers who are solely engaged in service or business maybe unable to devote 
adequate time to their children for providing adequate care as well as wholesome and healthy nutritious diet. In the present study, children from larger family size were less likely to be malnourished and this could be because in Nepal, children from larger family size receive care from several family members.

This study showed that $72 \%$ deliveries were institutional. The percentage of intuitional delivery is 57\% nationally, according to Annual report 2071/72 and 55.2\% nationally, according to MICS, 2014 (DoHS, 2016). The percentage of institutional delivery is higher in the study districts possibly because of effective implementation of Amma program. Almost $84 \%$ of the mothers in this study had attended school, which means that awareness on the importance of institutional delivery was better among these mothers. Children born from mothers who underwent institutional delivery were less likely to be malnourished as compared to children born from mothers who underwent home delivery. This could be because mothers who had institutional deliveries were more likely to be aware of good antenatal care, healthy feeding practices and good child care and had exposure to health workers' counseling. Height of mother is also one of the predictors for underweight. Children who born from a mother whose height is less than $145 \mathrm{~cm}$ were more likely to be underweight. The study conducted by Subramanian et. al. (2009) in India revealed that one $\mathrm{cm}$ increase in maternal height was associated with a decreased risk of underweight, stunting, wasting and child mortality. Children of mothers whose age at delivery was more than 35 years were more likely to be malnourished. This finding was supported by the study of Bhandari and Chhetri (2013) which was conducted in Kapilvastu district of Nepal.

\section{CONCLUSION}

A significant numbers of under-five children were malnourished in Lamjung, Gorkha and Tanahun. The prevalence of wasting, stunting and underweight among the children were $10.6 \%$. $53.9 \%$ and $20.8 \%$ respectively. Boys were more likely to be wasted, stunted and underweight compared to girls. The overall prevalence of stunting is higher as compare to wasting and underweight. The factors affecting the nutritional status of under 5 children were duration of breast feeding, occupation of mothers, family size, delivery site, height of mothers and age of mother during the delivery. Several positive and commendable steps have been taken to tackle malnutrition in Nepal. However, malnutrition remains a major public health problem in the Nepalese context. The various factors affecting malnutrition must be adequately dealt with by policy makers, planners, implementers and relevant stakeholders. Relevant policies, effective programmes and a wide variety of activities must be formulated and carried out with concerted efforts to tackle malnutrition in under five years children of Nepal. 


\section{CONFLICT OF INTEREST}

The author declared that there is no conflict of interest.

\section{ACKNOWLEDGEMENTS}

We are thankful to all respondents, children and family members for giving us valuable information. We are also thankful to all medical students for collection of data. We are grateful to the University Grants Commission (UGC) for the Mini Research Award.

\section{REFERENCES}

Bhandari, T. R., \& Chhetri, M. (2013). Nutritional status of under five year children and factors associated in Kapilvastu District, Nepal. J Nutr Health Food Sci, 1(1), 1-6.

Chataut, J., \& Khanal K. (2016). Assessment of nutritional status of children under five years of age in rural Nepal. Kathmandu Univ Med J, 53(1), 73-77.

Department of Health Services. (2016). Annual Report 2014/2015. Ministry of Health, Government of Nepal, Kathmandu, Nepal.

Dhungana, G. P. (2014). Nutritional status of under 5 children and associated factors of Kunchha village development committee. Journal of Chitwan Medical College, 3(4), 38-42.

Haileslassie, K., Mulugeta, A., \& Girma, M. (2013). Feeding practices, nutritional status and associated factors of lactating women in Samre Woreda, South Eastern Zone of Tigray, Ethiopia. Nutrition Journal, 12(1), 28.

Pandey, J. P., Dhakal, M. R., Karki, S., Poudel, P., \& Pradhan, M. S. (2013). Maternal and child health in Nepal: The effects of caste, ethnicity, and regional identity: Further analysis of the 2011 Nepal Demographic and Health Survey. Calverton, Maryland, USA, Nepal Ministry of Health and Population, New ERA, and ICF International.

Kumar, D., Goel, N. K., Mittal, P. C., \& Misra, P. (2006). Influence of infant-feeding practices on nutritional status of under-five children. Indian Journal of Pediatrics, 73(5), 417-421.

Lodhi, H. S., Lodhi, F. S., Wazir, S., Taimoor, A. R., \& Jadoon, H. (2009). Assessment of nutritional status of 1-5 year old children in an urban union council of Abbottabad. Journal of Ayub Medical College, Abbottabad: JAMC, 22(3), 124-127.

Masood-us-Syed, S. S., Saleh, M., \& Butt, Z. K. (2011). Nutritional assessment of children under the age of sixty months in District Sialkot, Pakistan. Journal of Pioneering Medical Sciences, $1(1), 7$.

Mengistu, K., Alemu, K., \& Destaw, B. (2013). Prevalence of malnutrition and associated factors among children aged 6-59 months at Hidabu Abote District, North Shewa, Oromia Regional State. J Nutr Disorders Ther, T1:001. 
National Planning Commission. (2015). Sustainable development goals 2016-2030: National (Preliminary) Report. Government of Nepal, Kathmandu, Nepal.

Nepal Ministry of Health and Population, New ERA and ICF International. (2012). Nepal demographic and health survey 2011. Kathmandu, Nepal.

Nungo, R. A., Okoth, M. W., \& Mbugua, S. K. (2012). Nutrition status of children under-five years in cassava consuming communities in Nambale, Busia of Western Kenya. $J$ Food and Nutrition Sciences, 3(6), 796.

Pradhan, A. (2010). Factors associated with nutritional status of the under five children. Asian Journal of Medical Sciences, 1(1), 6-8.

Ronsmans, C., Collin, S. \& S., Filippi. V. (2008). Maternal mortality in developing countries: Nutrition and health in developing countries (2nd ed.). USA: Humana Press.

Ruwali, D. (2012). Nutritional status of children under five years of age and factors associated in Padampur VDC, Chitwan. Health Prospect, 10, 14-18.

Sapkota, V.P., \& Gurung, C. K. (2009). Prevalence and predictors of underweight, stunting and wasting in under-five children. J Nepal Health Res Counc. 7(15), 120-126.

Subramanian, S. V., Ackerson, L. K., Smith, G. D., \& John, N. A. (2009). Association of maternal height with child mortality, anthropometric failure, and anemia in India. Jama, 301(16), 1691-1701.

UNICEF, WHO, \& The World Bank. (2016). Child malnutrition database. Retrieved from http://www.childinfo.org/malnutrition_dashboard.html

UNICEF. (2013). Nutritional status of under five children. Retrieved from www.unicef.org/publications/index.html

UNICEF. (2016). Infant and young child feeding global database. Retrieved from https://data.unicef.org/topic/nutrition/infant-and-young-child-feeding/

WHO. (2016). Global database on child growth and malnutrition.

Retrieved from http://www.who.int/nutgrowthdb/en.

WHO. (2006). World Health Organization child growth standards. Retrieved from www.who.int/childgrowth/en.

Peiris, T. D. R., \& Wijesinghe, D.G.N.G. (2010). Nutritional Status of under 5 year-old children and its relationship with maternal nutrition knowledge in Weeraketiya DS division of Sri Lanka. J Tropical Agricultural Research, 21(4), 330 - 339. 
Reference to this paper should be made as follows:

Dhungana, G. P. (2017). Nutritional status and the associated factors in under five years children of Lamjung, Gorkha and Tanahun districts of Nepal. Nep. J. Stat., 1, 15-28. 